\title{
Diagnostic error, quality assurance, and medical malpractice/risk management education in emergency medicine residency training programs
}

https://doi.org/10.1515/dx-2018-0079

Received August 15, 2018; accepted January 29, 2019; previously published online February 28, 2019

\begin{abstract}
Background: Diagnostic errors in emergency medicine (EM) can lead to patient harm as well as potential malpractice claims and quality assurance (QA) reviews. It is therefore essential that these topics are part of the core education of trainees. The methods training programs use to educate residents on these topics are unknown. The goal of this study was to identify the current methods used to teach EM residents about diagnostic errors, QA, and malpractice/ risk management and determine the amount of educational teaching time EM programs dedicate to these topics.

Methods: An 11-item questionnaire pertaining to resident education on diagnostic errors, QA, and malpractice was sent through the Council of Emergency Medicine Residency Directors (CORD) listserv. Differences in the proportions of responses by duration of training program were analyzed using chi-squared or Fisher's exact tests.

Results: Fifty-four percent (91/168) of the EM programs responded. There was no difference in prevalence of formal education on these topics among 3- and 4-year programs. The majority of programs (59.5\%) offer fewer than $4 \mathrm{~h}$ per year of additional QA education beyond morbidity and mortality rounds; a minority of the programs $(18.8 \%)$ offer more than $4 \mathrm{~h}$ per year of medical malpractice/risk management education.
\end{abstract}

\footnotetext{
*Corresponding author: Jason J. Lewis, MD, Department of Emergency Medicine, Beth Israel Deaconess Medical Center and Harvard Medical School, One Deaconess Road, Rosenberg 2, Boston, MA 02215, USA, Phone: 617-754-2450, E-mail: jlewis@bidmc.harvard.edu

Carlo L. Rosen, Anne V. Grossestreuer, Edward A. Ullman and Nicole M. Dubosh: Department of Emergency Medicine, Beth Israel Deaconess Medical Center and Harvard Medical School, Boston, MA, USA, E-mail: crosen2@bidmc.harvard.edu (C. L. Rosen); agrosses@bidmc.harvard.edu (A. V. Grossestreuer); eullman@bidmc.harvard.edu (E. A. Ullman); ndubosh@bidmc.harvard.edu (N. M. Dubosh)
}

Conclusions: This needs assessment demonstrated that there is a lack of dedicated educational time devoted to these topics. A more formalized and standard curricular approach with increased time allotment may enhance EM resident education about diagnostic errors, QA, and malpractice/risk management.

Keywords: diagnostic error; malpractice; quality assurance; resident education; risk management.

\section{Introduction}

Diagnostic errors in medicine pose a significant burden to patients, providers, and the overall healthcare system, leading to increased morbidity and mortality and significant financial implications. Diagnostic errors are estimated to occur in at least $5 \%$ of patients in the outpatient setting $[1,2]$ and up to $17 \%$ of in-hospital adverse events are attributed to diagnostic error [2]. In Emergency Medicine (EM), the true diagnostic error rate is unknown. Prior studies on the topic estimate this to be anywhere from $0.6 \%$ to $35 \%$ of cases depending on the chief complaint [3-5]. Diagnostic errors affect patient outcomes and trigger quality assurance (QA), risk management, and medical malpractice actions. Prior work suggests that diagnostic errors result in 40,000-80,000 deaths annually in the Unites States [6, 7]. They also represent 29-35\% of malpractice claims and result in the highest proportion of malpractice payouts [8-10]. Diagnostic error is a significant issue for quality assurance (QA) and patient safety initiatives and is a public health imperative $[2,11,12]$.

Diagnostic error is multifactorial with contributions from both systems and cognitive factors [13, 14]. Common causes include breakdown in the patient-physician encounter and follow-up [4, 9, 14, 15]. Errors (along with resulting malpractice cases) could potentially be reduced through resident education on diagnostic error and strategies to avoid it. The Accreditation Council for Graduate Medical Education (ACGME) common program requirements mandate resident participation in quality improvement and patient safety education [16]. However, the 
methods and dedicated time training programs use to educate residents on the topics of diagnostic errors, QA and malpractice/risk management are unknown.

The objectives of our study were to identify the current methods used to teach EM residents about diagnostic errors, QA, and malpractice/risk management and to determine the educational time EM training programs dedicate to teaching these topics. As diagnostic error interplays significantly with both malpractice and QA, we focused on the time allotted to these latter specific topics. Additionally, as EM residencies have both 3- and 4-year models, we aimed to determine if there was a difference in educational time dedicated to these topics by program length.

\section{Materials and methods}

We conducted a survey study of EM residency directors of ACGMEaccredited programs. The medical education team at our institution, which included the residency director and medical student clerkship directors, as well as our quality assurance leadership, developed an 11-item questionnaire (see Supplementary Material, Appendix 1). Respondents were asked to identify the name of their program (to avoid redundancy of responses) and to identify the length of their residency program. Nationwide in the United States, $71 \%$ of EM residency programs are 3-year programs, and the remaining are 4-year programs [17]. The survey examined what modalities were used to teach the following topics: diagnostic errors, QA, and malpractice/ risk management education. The survey was piloted among the medical education faculty within our department for ease of use, and the authors made minor modifications for clarity based on feedback.

Through the Council of Emergency Medicine Residency Directors (CORD) listserv, we identified 168 ACGME-accredited EM Programs. The survey was emailed to the CORD listserv in September 2015 and a reminder email was sent 2 weeks later. Four weeks after the initial survey request, program directors of residencies who did not complete the survey were contacted individually by email and asked to respond. Responses were recorded in a REDCap database [18]. Duplicate responses from individual programs were removed, with the first response from a program being used. Additionally, as the CORD listserv also included non-ACGME-accredited programs, responses from programs not included in the identified
168 ACGME-accredited programs were removed. Results were deidentified prior to data analysis and stored on a secure server. Differences in the proportions of responses by duration of training program ( 3 vs. 4 years) were analyzed using chi-squared or Fisher's exact tests, as appropriate. Analysis was performed using Stata 14.2 (College Station, TX, USA). This study was reviewed by the Institutional Review Board at our institution and determined exempt from further review.

\section{Results}

Fifty-four percent (91/168) of the EM programs responded. There was no difference in prevalence of formal education on these topics among 3- and 4-year programs (Table 1). The different educational modalities used by programs are shown in Table 2 . The majority of programs (59.5\%) offer fewer than $4 \mathrm{~h}$ per year of additional QA education beyond morbidity and mortality (M\&M) rounds (Table 3); fewer programs (18.8\%) offer more than $4 \mathrm{~h}$ per year of medical malpractice/risk management education (Table 4).

\section{Discussion}

The results of our study demonstrate that the majority of ACGME-certified EM residency programs who responded to our survey offer formal didactics on diagnostic errors, $\mathrm{QA}$, and medical malpractice/risk management. The modalities of education are varied, and the majority of programs offer fewer than $4 \mathrm{~h}$ of dedicated educational time on QA and medical malpractice/risk management.

Resident education on diagnostic error is currently evolving. Several curricular interventions on these topics have been proposed in the literature. Ruedinger et al. described a 6-month longitudinal curriculum incorporating interactive lectures, small group discussions, case analysis, case conference, and an interactive faculty panel over three distinct sessions encompassing $9 \mathrm{~h}$ of

Table 1: Proportion of programs offering formal teaching on diagnostic error, quality assurance, malpractice/risk management.

\begin{tabular}{|c|c|c|c|}
\hline & 3-Year program $(n=60)$ & 4-Year program $(n=31)$ & p-Value \\
\hline $\begin{array}{l}\text { Does your program include formal, required didactics on diagnostic errors and } \\
\text { misdiagnosis? }\end{array}$ & $85.0^{\mathrm{a}}$ & 77.4 & 0.394 \\
\hline $\begin{array}{l}\text { Does your program include formal, required didactics on quality assurance (QA) } \\
\text { including root-cause analysis? }\end{array}$ & 90.0 & 83.9 & 0.500 \\
\hline $\begin{array}{l}\text { Does your program offer formal, required didactics on medical malpractice and } \\
\text { risk management? }\end{array}$ & 79.7 & 74.2 & 0.599 \\
\hline Are residents in your program required to participate in departmental QA review? & 88.3 & 93.6 & 0.713 \\
\hline
\end{tabular}

aPercent of programs answering affirmatively. 
Table 2: Educational modalities used for teaching diagnostic errors, quality assurance, and medical malpractice/risk management.

\begin{tabular}{|c|c|c|c|}
\hline & 3-Year program & 4-Year program & p-Value \\
\hline Diagnostic errors and misdiagnosis & $\mathrm{n}=51$ & $\mathrm{n}=24$ & \\
\hline Morbidity and mortality (M\&M) conference & $48(94.1)$ & $23(95.8)$ & $>0.999$ \\
\hline Lectures & $36(70.6)$ & $21(87.5)$ & 0.150 \\
\hline Simulation cases & $27(52.9)$ & $8(33.3)$ & 0.140 \\
\hline Small-group discussions & $24(47.1)$ & $11(45.8)$ & 0.921 \\
\hline Web-based modules & $14(27.5)$ & $4(16.7)$ & 0.392 \\
\hline Other & $0(0)$ & $2(8.3)$ & 0.099 \\
\hline Administrative rotation ${ }^{\mathrm{a}}$ & $0(0)$ & $1(4.2)$ & \\
\hline Quality improvement meeting attendance and participation & $0(0)$ & $1(4.2)$ & \\
\hline Quality assurance including root-cause analysis & $\mathrm{n}=54$ & $n=26$ & \\
\hline Morbidity and mortality (M\&M) conference & $32(59.3)$ & $12(46.2)$ & 0.270 \\
\hline Lectures & $29(53.7)$ & $12(46.2)$ & 0.527 \\
\hline Participation at departmental quality assurance committee meetings & $29(53.7)$ & $16(61.5)$ & 0.508 \\
\hline Small-group discussions & $10(18.5)$ & $4(15.4)$ & $>0.999$ \\
\hline Web-based modules & $10(18.5)$ & $4(15.4)$ & $>0.999$ \\
\hline Other & $2(3.7)$ & $4(15.4)$ & 0.084 \\
\hline Mock root-cause analysis & $2(3.7)$ & $1(3.8)$ & \\
\hline Administrative rotation ${ }^{\mathrm{a}}$ & $0(0)$ & $1(3.8)$ & \\
\hline Theme days $^{\mathrm{b}}$ & $0(0)$ & $1(3.8)$ & \\
\hline Not specified & $0(0)$ & $1(3.8)$ & \\
\hline Medical malpractice and risk management & $n=47$ & $n=23$ & \\
\hline Morbidity and mortality (M\&M) conference & $19(40.4)$ & $12(52.2)$ & 0.353 \\
\hline Lectures & $44(93.6)$ & $20(87.0)$ & 0.387 \\
\hline Simulation cases & $5(10.6)$ & 4 (17.4) & 0.463 \\
\hline Small-group discussions & $12(25.5)$ & $7(30.4)$ & 0.776 \\
\hline Web-based modules & 7 (14.9) & $4(17.4)$ & $>0.999$ \\
\hline Other & $4(8.5)$ & $1(4.5)$ & $>0.999$ \\
\hline Mock trial/deposition & $3(6.4)$ & $1(4.5)$ & \\
\hline High Risk EM Course & $1(2.1)$ & $0(0)$ & \\
\hline
\end{tabular}

${ }^{\text {a }}$ Four-week administrative rotation during the fourth-year of residency including administrative meetings with operations leadership with discussion on patient safety initiatives, participation in continuous quality improvement initiatives and participation in a quality improvement project. ${ }^{\text {} T}$ Theme days are a multimodal approach comprising primer readings, a brief anchoring lecture of approximately $15 \mathrm{~min}$, followed by $4 \mathrm{~h}$ small group discussion and a large group synthesis of a root-cause analysis with the goal of understanding and participating in the entire process.

Table 3: Total hours of formal, required didactics on quality assurance other than a morbidity and mortality (M\&M) conference per academic year.

\begin{tabular}{|c|c|c|c|c|}
\hline & Overall $(n=79)$ & 3-Year program $(n=53)$ & 4-Year program $(n=26)$ & p-Value \\
\hline $0-2 \mathrm{~h}$ & $21(26.6)$ & $14(26.4)$ & 7 (26.9) & 0.551 \\
\hline $2-4 \mathrm{~h}$ & $26(32.9)$ & $20(37.7)$ & $6(23.1)$ & \\
\hline $4-6 h$ & $16(20.3)$ & $9(17.0)$ & 7 (26.9) & \\
\hline$>6 \mathrm{~h}$ & $16(20.3)$ & $10(18.9)$ & $6(23.1)$ & \\
\hline
\end{tabular}

Table 4: Total hours of formal, required didactics on medical malpractice/risk management per academic year.

\begin{tabular}{|c|c|c|c|c|}
\hline & Overall $(n=69)$ & 3-Year program $(n=47)$ & 4-Year program $(n=22)$ & p-Value \\
\hline $0-2 \mathrm{~h}$ & $28(40.6)$ & $18(38.3)$ & $10(45.5)$ & 0.602 \\
\hline $2-4 \mathrm{~h}$ & $28(40.6)$ & $21(44.7)$ & $7(31.8)$ & \\
\hline $4-6 h$ & 7 (10.1) & $5(10.6)$ & $2(9.1)$ & \\
\hline$>6 \mathrm{~h}$ & $6(8.7)$ & $3(6.4)$ & $3(13.6)$ & \\
\hline
\end{tabular}


education time. Residents found the curriculum helpful and had improved awareness of strategies to reduce cognitive error [19]. Likewise, Reilly et al. developed a longitudinal 1-year curriculum on diagnostic errors and cognitive bias comprised of didactics, case-based discussion, small group narratives, and an online module divided into three separate sessions, which improved Internal Medicine residents' knowledge and awareness of cognitive bias [20]. While EM programs in our study utilized a variety of educational modalities for education on diagnostic errors including simulation and small group discussions, M\&M and lecture were the most frequent approaches. EM programs may consider devoting more time to other modalities such as small group discussion, case-based learning, and web-based modules to expand resident education on diagnostic error.

Educational initiatives on diagnostic error in EM should include discussions about the cognitive and systems factors that contribute to diagnostic errors. Croskerry highlights the dual process model of reasoning for clinical decision-making and diagnostic error [21]. He has also extensively described specific cognitive biases, how they lead to errors, and strategies for cognitive debiasing including metacognition [22, 23]. Additionally, various strategies have been shown (or suggested) to reduce errors including checklists, structured processes for patient handoffs, and the "diagnostic time-out" [24-26]. An understanding of these cognitive and systems-based mechanisms is imperative for understanding diagnostic errors and should be included in curriculum development efforts.

In addition to new educational curriculum focusing on diagnostic error, several EM curricula focusing on medical malpractice have been proposed. Houry and Shockley developed a formalized 1-week curriculum during which EM residents reviewed malpractice cases and observed settlement discussions with a malpractice insurance company, which resulted in an improved understanding of the medicolegal aspects of EM practice [27]. Schlicher and Ten Eyck utilized a layered simulation session involving a case with an adverse outcome and subsequent simulated deposition. EM residents rated this curriculum highly [28]. In our study, only $10 \%$ of 3-year programs and $17 \%$ of 4 -year programs utilized simulation cases. Further studies are needed to assess the efficacy of traditionally used teaching modalities (i.e. M\&M conference, lectures) as well as more novel techniques.

One of the most common teaching modalities utilized by residency programs for all topics was M\&M rounds. While M\&M rounds can provide valuable clinical education, they may not analyze the intricacies of medical malpractice/risk management [27, 29]. This can lead to an overall lack of legal knowledge as well as inexperience with malpractice case reviews [27, 29]. In a recent analysis of over 350,000 open and closed EM malpractice claims, Gurley et al. found that residents were named in 13\% of cases and that resident cases were characterized as higher in severity [30]. Given this substantial percentage and the downstream consequences entailed in malpractice claims as well as the significant contribution of diagnostic error to over $25 \%$ of malpractice cases and $35 \%$ of malpractice payouts [10], it is imperative that residency programs provide education on these topics early in training.

The lack of dedicated teaching time towards these topics, as demonstrated in our study, is not limited to EM. Ruedinger et al. note that formal education on diagnostic errors is lacking in many graduate medical education programs [19]. In one survey of medicolegal knowledge of Family Medicine residents, respondents noted a lack of knowledge of medicolegal issues [31]. Likewise, over $70 \%$ of medical chief residents felt that their training on medicolegal issues was insufficient [32]. Furthermore, the American Academy of Pediatrics states that residents and fellows must be educated on matters relating to medical liability by their training programs [33]. Given these findings and recommendations as well as the paucity of dedicated educational time we found in our survey, a standardized approach for teaching these topics across multiple specialties may be beneficial and allow for interdepartmental collaboration.

Our study serves as a needs assessment for improvement in EM resident education. A new standardized curriculum incorporating high-yield lectures by legal counsel, faculty panels, participation in review of cases and depositions with the residency malpractice insurance provider, layered simulation cases on diagnostic error, and participation in departmental QA review process has the potential to enhance resident comfort and understanding of these important topics.

\section{Limitations}

This study has several limitations. First, given the variability in educational curriculum and the survey methodology, the exact categorization of QA, diagnostic error, risk management/malpractice may differ among programs. The terminology used in the survey, such as "formal required didactics", may not be interpreted in the same manner by every program and this may have influenced the results. The terminology is slightly different from that used in the EM milestones project and may have been interpreted 
differently by survey participants. It is unknown if education on risk management/medical malpractice, diagnostic errors, and QA influences the likelihood of making a diagnostic error or being involved in a medical malpractice case.

\section{Conclusions}

The majority of EM programs have formal education on diagnostic errors, QA, malpractice/risk management. The modalities for teaching these topics vary across programs and the overall number of educational hours devoted to QA and malpractice/risk management is low. A more formalized curricular structure with increased time allotment in the residency educational curriculum may prove enhance resident knowledge of these patient safety and health care quality issues.

Author contributions: All the authors have accepted responsibility for the entire content of this submitted manuscript and approved submission.

Research funding: None declared.

Employment or leadership: None declared.

Honorarium: None declared.

Competing interests: The funding organization(s) played no role in the study design; in the collection, analysis, and interpretation of data; in the writing of the report; or in the decision to submit the report for publication.

\section{References}

1. Singh H, Meyer AN, Thomas EJ. The frequency of diagnostic errors in outpatient care: estimations from three large observational studies involving US adult populations. BMJ Qual Saf 2014;23:727-31.

2. National Academies of Sciences, Engineering, and Medicine. Improving diagnosis in health care. Washington, DC: National Academies Press, 2015.

3. Chellis M, Olson J, Augustine J, Hamilton GC. Evaluation of missed diagnoses for patients admitted from the emergency department. Acad Emerg Med 2001;8:125-30.

4. Medford-Davis L, Park E, Shlamovitz G, Suliburk J, Meyer AN, Singh H. Diagnostic errors related to acute abdominal pain in the emergency department. Emerg Med J 2016;33:253-9.

5. Vermeulen MJ, Schull MJ. Missed diagnosis of subarachnoid hemorrhage in the emergency department. Stroke 2007;38:1216-21.

6. Newman-Toker DE, Pronovost PJ. Diagnostic errors - the next frontier for patient safety. JAMA 2009;301:1060-2.

7. Graber ML. The incidence of diagnostic error in medicine. BMJ Qual Saf 2013;22:ii21-7.

8. Brown TW, McCarthy ML, Kelen GD, Levy F. An epidemiologic study of closed emergency department malpractice claims in a national database of physician malpractice insurers. Acad Emerg Med 2010;17:553-60.

9. Kachalia A, Gandhi TK, Puopolo AL, Yoon C, Thomas EJ, Griffey $\mathrm{R}$, et al. Missed and delayed diagnoses in the emergency department: a study of closed malpractice claims from 4 liability insurers. Ann Emerg Med 2007;49:196-205.

10. Saber Tehrani AS, Lee HW, Mathews SC, Shore A, Makary MA, Pronovost PJ, et al. 25-Year summary of US malpractice claims for diagnostic errors. BMJ Qual Saf 2013;22:672-80.

11. Singh H, Schiff GD, Graber ML, Onakpoya I, Thompson MJ. The global burden of diagnostic errors in primary care. BMJ Qual Saf 2017;26:484-94.

12. Khullar $D$, Jha $A K$, Jena $A B$. Reducing diagnostic errors - why now? N Engl J Med 2015;373:2491-3.

13. Graber ML, Franklin N, Gordon R. Diagnostic error in internal medicine. Arch Intern Med 2005;165:1493-9.

14. Hoffman J, editor. 2014 Annual benchmarking report: malpractice risks in the diagnostic process. Cambridge, MA: CRICO strategies, 2014.

15. Singh H, Giardina TD, Meyer AN, Forjuoh SN, Reis MD, Thomas EJ. Types and origins of diagnostic errors in primary care settings. JAMA Intern Med 2013;173:418-25.

16. Accreditation Council for Graduate Medical Education. ACGME Common Program Requirements (Residency). Available at: https://www.acgme.org/Portals/0/PFAssets/ProgramRequirements/CPRResidency2019.pdf. Accessed: 24 Jul 2018.

17. Society for Academic Emergency Medicine. Residency Directory. Available at: http://saem.org/resources/directories/residencydirectory. Accessed: 15 Nov 2018.

18. Harris P, Taylor R, Thielke R, Payne J, Gonzalez N, Conde JG. Research electronic data capture (REDCap) - a metadata-driven methodology and workflow process for providing translational research informatics support. J Biomed Inform 2009;42:377-81.

19. Ruedinger E, Olson M, Yee J, Borman-Shoap E, Olson AP. Education for the next frontier in patient safety: a longitudinal resident curriculum on diagnostic error. Am J Med Qual 2017;32:625-31.

20. Reilly JB, Ogdie AR, Von Feldt JM, Myers JS. Teaching about how doctors think: a longitudinal curriculum in cognitive bias and diagnostic error for residents. BMJ Qual Saf 2013;22:1044-50.

21. Croskerry P. Clinical cognition and diagnostic error: applications of a dual process model of reasoning. Adv Health Sci Educ 2009;14:27-35.

22. Croskerry P. The cognitive imperative thinking about how we think. Acad Emerg Med 2000;7:1223-31.

23. Croskerry P. The importance of cognitive errors in diagnosis and strategies to minimize them. Acad Med 2003;78:775-80.

24. Pronovost P, Needham D, Berenholtz S, Sinopoli D, Chu H, Cosgrove $\mathrm{S}$, et al. An intervention to decrease catheterrelated bloodstream infections in the ICU. N Engl J Med 2006;355:2725-32.

25. Starmer AJ, Sectish TC, Simon DW, Keohane C, McSweeney ME, Chung EY, et al. Rates of medical errors and preventable adverse events among hospitalized children following implementation of a resident handoff bundle. J Am Med Assoc 2013;310:2262-70.

26. Trowbridge RL. Twelve tips for teaching avoidance of diagnostic errors. Med Teach 2008;30:496-500.

27. Houry D, Shockley LW. Evaluation of a residency program's experience with a one-week emergency medicine resident rotation 
at a medical liability insurance company. Acad Emerg Med 2001;8:765-7.

28. Schlicher NR, Ten Eyck RP. Medical malpractice: utilization of layered simulation for resident education. Acad Emerg Med 2008;15:1175-80.

29. Ott CJ, Houry DE. Medical malpractice and the emergency medicine resident. Ann Emerg Med 2000;36:631-3.

30. Gurley KL, Grossman SA, Janes M, Yu-Moe CW, Song E, Tibbles $C D$, et al. Comparison of emergency medicine malpractice cases involving residents to non-resident cases. Acad Emerg Med 2018;25:980-6.
31. Saltstone SP, Saltstone R, Rowe, BH. Knowledge of medicallegal issues. Survey of Ontario family medicine residents. Can Fam Physician 1997;43:669-73.

32. Kollas CD. Chief residents' medicolegal knowledge. Acad Med 1996;71:417-8.

33. Committee on Medical Liability and Risk Management, Gonzalez JL. Professional liability insurance and medicolegal education for pediatric residents and fellows. Pediatrics 2011;128:624-9.

Supplementary Material: The online version of this article offers supplementary material (https://doi.org/10.1515/dx-2018-0079). 